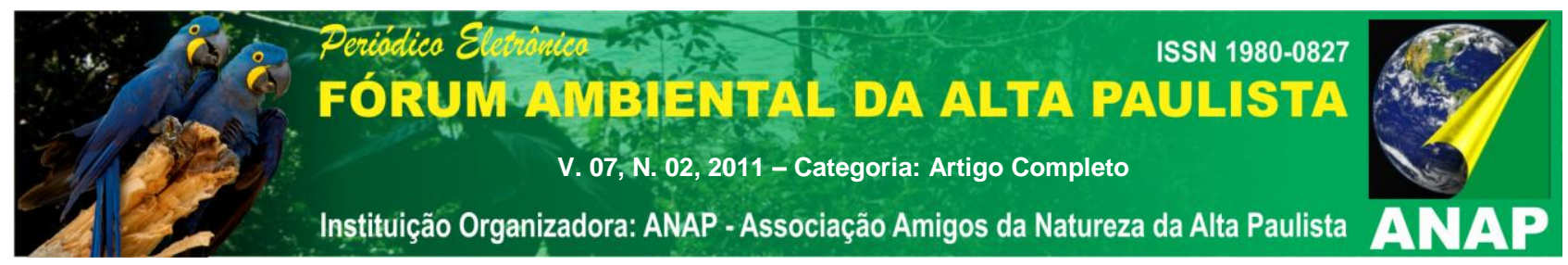

\title{
INUNDAÇÕES URBANAS: O CASO DA MICRO-BACIA HIDROGRÁFICA DO CÓRREGO IPIRANGA - JUIZ DE FORA/MG
}

\author{
Rafael Santos Silva ${ }^{1}$ \\ Pedro José Oliveira Machado²
}

Resumo: O trabalho "Inundações Urbanas: o caso da Micro-Bacia Hidrográfica do Córrego Ipiranga - Juiz de Fora/MG" é um estudo de caso sobre as ocorrências de inundações que ocorrem na micro-bacia do Córrego Ipiranga. O objetivo é identificar os pontos que ocorrem impactos ambientais, que tem como causa as inundações, que geram prejuízos materiais para a população local. No local, mesmo com repetidos casos anuais de impactos ambientais urbanos não há ações do poder púbico em prática como o seu planejamento e o gerenciamento para solucionar esse problema. As metodologias utilizadas foram as visitas de campo, análises morfometricas e edição de mapas com o software ArcGis 9.3 que auxiliaram na verificação do contraste existente entre o uso do solo e o seu relevo, e entre a forma da bacia e a ocupação urbana. Os impactos gerados são decorrentes da falta de planejamento e gerenciamento das bacias que junto com a não aplicação das leis existentes, prejudicam e degradam cada vez mais o ambiente em que os homens estão inseridos.

Palavras-chave: Bacias Hidrográficas. Impactos ambientais. Planejamento de bacias

\section{INTRODUÇÃO}

O crescimento urbano intenso e sem planejamento pode provocar impactos ambientais que modificam as condições naturais de uma determinada região. $\mathrm{O}$ modelo desordenado das ocupações urbanas e o aumento da impermeabilização do solo são

${ }^{1.1}$ Graduando em Geografia, Universidade Federal de Juiz de Fora. rafasantsilv@yahoo.com.br

2. 2 Orientador, Doutorando em Geografia, Universidade Federal do Rio de Janeiro. pjomachado@gmail.com 


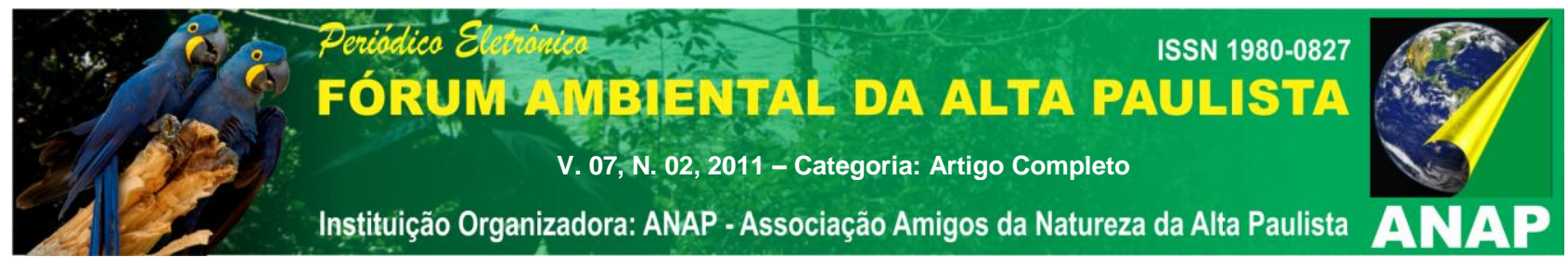

fatores determinantes para diminuir a infiltração, aumentar o escoamento superficial e consequentemente modificar o ciclo das águas nas cidades.

A urbanização, como toda obra que interpõe estruturas pouco permeáveis entre o solo e a chuva, faz com que o escoamento seja incrementado e que a infiltração diminua, em uma mudança de regime de escoamento localmente mais drástica do que aquela provocada pelo desmatamento (FENDRICH, IWASA, 1998 apud VENDRAME, LOPES, 2005).

O impacto principal devido à urbanização sobre um sistema de drenagem é o aumento do pico da vazão de cheia, a antecipação no tempo desta vazão máxima e o aumento do volume do escoamento superficial que pode ter como consequência, inundações que prejudiquem a população do entorno (VENDRAME; LOPES, 2005).

O desenvolvimento urbano produz aumento significativo na frequência de inundações, risco de deslizamentos de massa, produção de sedimentos e deterioração da qualidade da água. A falta de planejamento (ou omissão do poder público) na área urbana pode gerar preocupações para a população, especialmente de baixa renda, que vive em áreas de riscos sem infra-estrutura adequada e que convive com a ocorrência de fenômenos diversos que colocam suas vidas em risco.

Atualmente, na maior parte das cidades brasileiras, observa-se uma falta de planejamento para resolver os problemas de inundações. Casos atuais nas duas principais cidades do país (São Paulo e Rio de Janeiro), são exemplos de que as cidades estão sem investimento governamental para controlar e dar por menores os problemas vividos com relação aos cursos d'águas. 


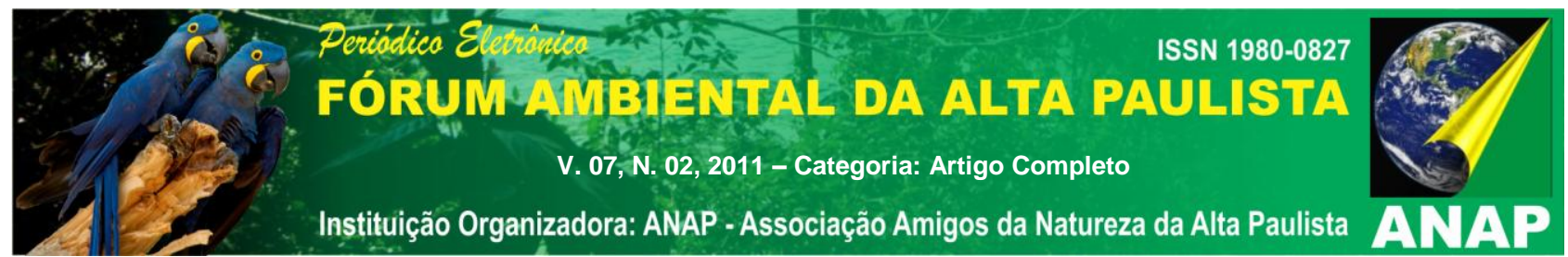

Assim como nas grandes cidades, que apresentam problemas ambientais e sofrem com as inundações, na Micro-Bacia do Córrego Ipiranga ( $\mathrm{MBCl}$ ) na cidade de Juiz de Fora - MG, não é diferente.

Na Área Urbana do Município de Juiz de Fora, existem 156 sub-bacias de diversas dimensões (CESAMA, 2011). Entre elas encontra-se a $\mathrm{MBCI}$ que tem uma área de aproximadamente 21 hectares.

Com o processo histórico de ocupação e com as modificações que ocorreram na $\mathrm{MBCl}$, várias mudanças ocorreram no local como as impermeabilizações, canalização do córrego, retirada de meandros (retificação do canal) e construções em geral que ocasionam o aumento de probabilidades na ocorrência de inundações.

A definição para inundações é a seguinte:

tipo particular de enchente, onde a elevação do nível d'água normal atinge tal magnitude que as águas não se limitam à calha principal do rio, extravasando para áreas marginais, habitualmente não ocupadas pelas águas IGCE/DGA (2004).

Seguindo a linha de pesquisa do IGCE/DGA (2004) há dois condicionantes para realização de tais fenômenos que é a condicionante natural e a condicionante da ação antrópica.

A condicionante natural da enchente ou inundação é causada por vários motivos como: pela forma da bacia hidrográfica, forma do vale, topografia da várzea, estrangulamento da drenagem, ausência da vegetação na área da bacia hidrográfica, permeabilidade do solo na área da bacia, clima (pluviosidade).

A condicionante antrópica facilita a ocorrência de inundações e a partir de vários motivos também, como: assoreamento do canal de drenagem, interceptação/estrangulamento da drenagem (barramentos), desmatamento, impermeabilização dos terrenos, lançamento de águas servidas e esgoto na drenagem, águas pluviais rapidamente conduzidas para a drenagem, elevada densidade de edificação (ilha de calor). 


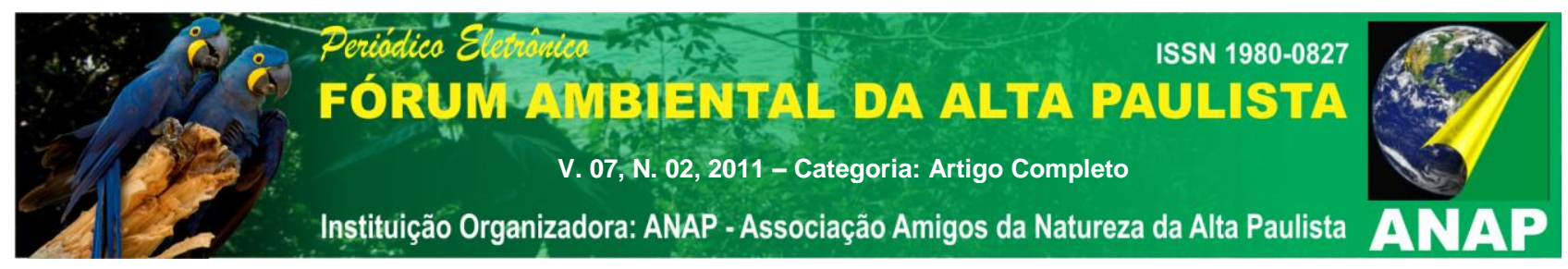

Diante disso, os objetivos desse trabalho são verificar as condições de ocorrência de inundações que podem prejudicar a população que vive no local e destacar a falta de planejamento na micro-bacia hidrográfica do córrego Ipiranga na cidade de Juiz de Fora - MG.

A $\mathrm{MBCl}$ tem $10 \%$ do total da população de Juiz de Fora (Anuário Estatístico, 2010) que tem aproximadamente 517 mil habitantes (IBGE, 2011). Observe no mapa a concentração urbana na micro-bacia a partir da imagem georreferenciada do Google Earth, do ano de 2005.

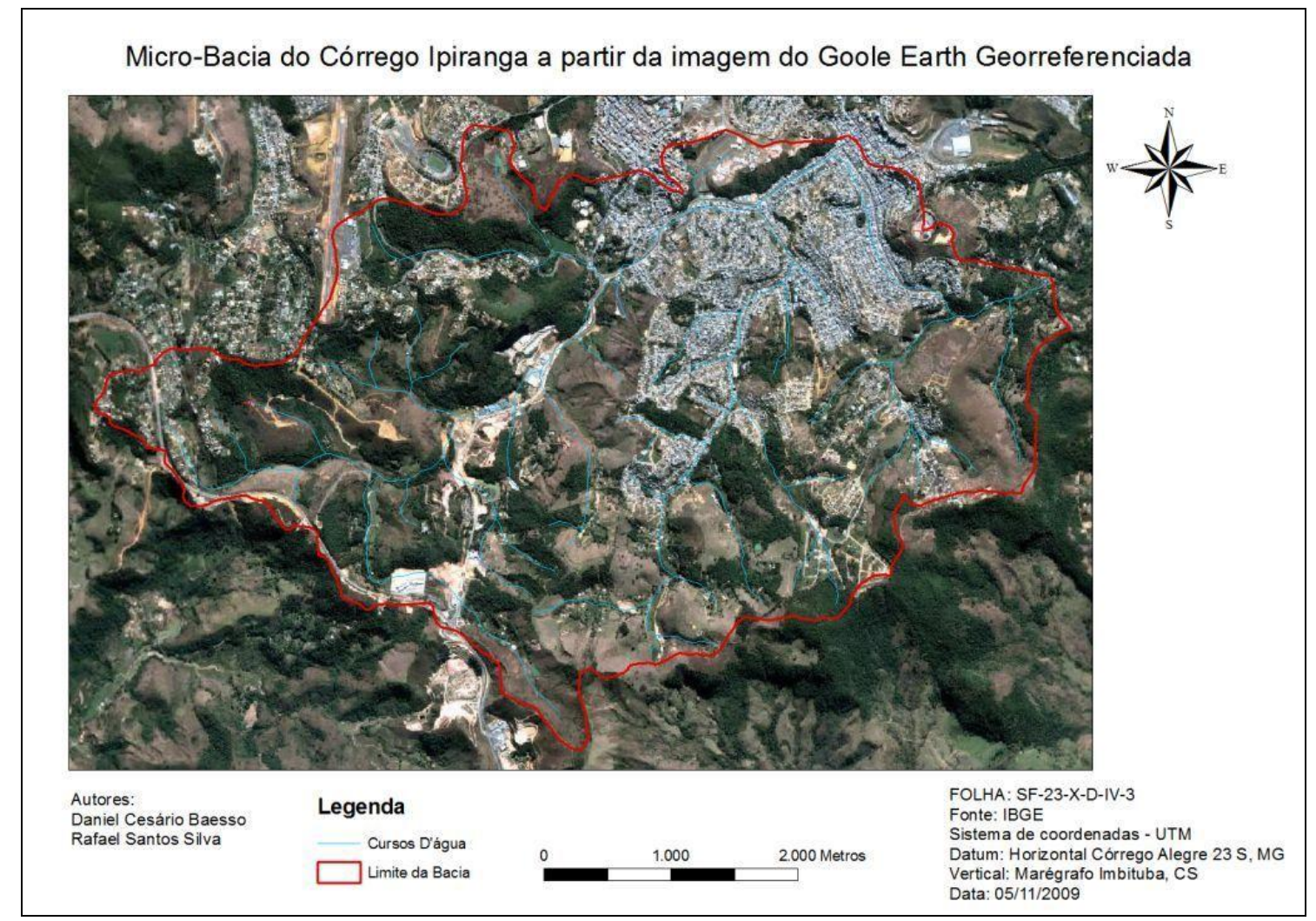

Mapa 1: Delimitação da micro-bacia a partir da imagem georreferenciada do Google Earth. Fonte:

arquivo pessoal do autor, 2011

A prefeitura da cidade de Juiz de Fora atualmente tem programas que estão sendo vigentes para reconstruir a cidade reformando as ruas, praças, construção de hospitais, etc., mas não há nos programas, projetos que visam o planejamento das bacias hidrográficas, represas, melhor fornecimento de qualidade de água, proteção das matas, etc., ou seja, programas que se importam com o meio ambiente. 


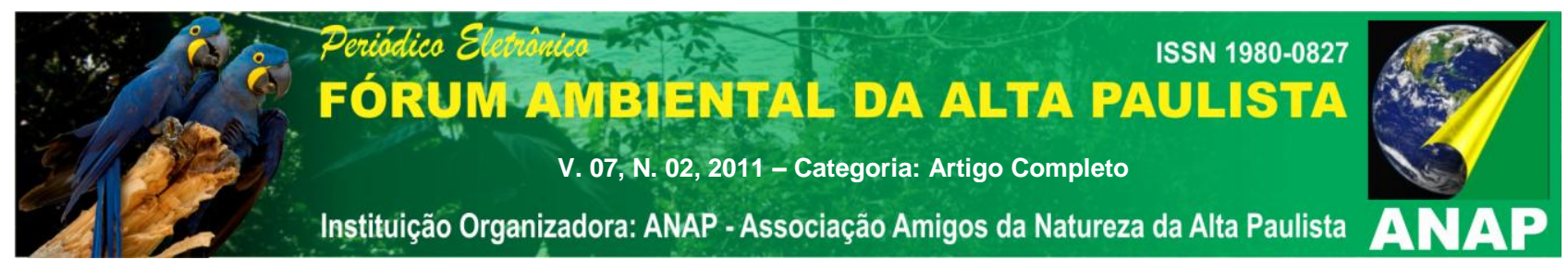

O planejamento das bacias hidrográficas se faz importante pois

\begin{abstract}
se constitui num sistema natural bem delimitado geograficamente, onde os fenômenos e interações podem ser integrados a priori pelo input e output, assim bacias hidrográficas podem ser tratadas como unidades geográficas, onde os recursos naturais se integram. Além disso, constitui-se uma unidade espacial de fácil reconhecimento e caracterização, [...] a solução deve estar estreitamente ligada ao seu manejo e manutenção (SANTOS, 2004 apud NASCIMENTO, 2008)
\end{abstract}

Há muitos estudos sobre as bacias na qual afirmam a importância do planejamento delas, só que não temos muitos municípios que apóiam e efetivam esses estudos melhorando a qualidade de vida de sua população e do meio ambiente.

A metologia utilizada foram os seguintes instrumentos de pesquisa:visitas de campo, uso do software Arcgis 9.3 para criação de mapas e estudo bibliográfico.

Para a elaboração de mapas, é utilizado como instrumento de pesquisa o software Arcgis na versão 9.3, que possibilitou a construção de mapas de declividade, curva de nível, 3D, limite da micro-bacia, entre outros. Com os mapas é possível ter uma visualização espacial do local e suas especificidades, para posterior análise das características da micro-bacia, com finalidade de encontrar as áreas que tem a maior facilidade de ocorrência de inundações.

Nas visitas de campo foram observados os pontos de maior instabilidade que têm probabilidades ocorrência de inundações. Essas visitas de campo foram realizadas nos meses de maiores precipitações (dezembro, janeiro e fevereiro). Além de observar os pontos, foram feitos diálogos com residentes nesses locais que relataram ocasiões em que puderam registrar os prejuízos que sofreram por seguidos anos em que não houve nenhuma melhora do local.

\title{
2 DESENVOLVIMENTO
}

\subsection{Caracterização da micro-bacia}

A MBCl fica ao sul da cidade de Juiz de Fora. A urbanização do local se iniciou no principio de 1930 onde se localizava uma fazenda com o nome de "cachoeirinha". $\mathrm{Na}$ 


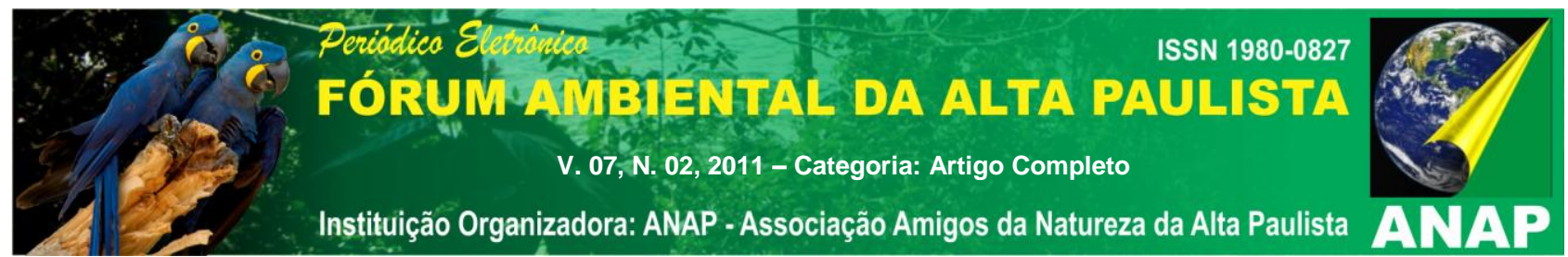

fazenda se encontrava cafezais, arrozais, currais. Posteriormente a fazenda trocou de dono e a mesma foi loteada (MARTINS, 2007).

O loteamento e a comercialização dos lotes foram feitas sem mesmo a área possuir qualquer tipo de infra-estrutura (não tinha saneamento básico, nem calçamento, luz elétrica, etc) nos anos de 1940. A ocupação foi feita próximo ao córrego, onde há maiores riscos de inundações. Devido a isso, houve sérios problemas de saúde para a população local, que devido à falta de higiene nas ruas, foi necessário executar obras de saneamento para retificar, canalizar e fazer o rebaixamento do córrego (MARTINS, 2007; BENTO, 2009).

Com as obras de saneamento prontas, o número da população no local aumento significativamente (BENTO, 2009). As obras (emergenciais) que foram feitas para melhorar os problemas de saúde, geraram a retirada da mata ciliar, desconfiguração do escoamento superficial, menor infiltração, facilidade de maior erosão da áreas, impermeabilização do local, entre outros. Segudo CROCHET, (s/d) apud MARTINS (2009) devido ao rápido crescimento, a comunidade ganhou maior infra-estrutura onde a expansão da malha urbana aumentou progressivamente.

\subsection{Análise Morfométrica da $\mathrm{MBCl}$}

A micro-bacia do córrego Ipiranga tem uma área de aproximadamente 21 hectares e o rio principal tem aproximadamente 10.300 metros de extensão. A geomorfologia do local tem amplitudes de $200 \mathrm{~m}$ e fica na área do Complexo Juiz de Fora.

Quanto à classificação do curso d'água, a $\mathrm{MBCl}$ pode ser classificada como Perene devido o curso do mesmo conter água durante todo o ano. Para um curso d'água ser caracterizado como perene é necessário que o lençol subterrâneo mantenha uma alimentação contínua e não desça nunca abaixo do leito do curso d'água, mesmo durante as secas mais severas. (MACHADO, 2008).

A $\mathrm{MBCl}$ apresenta um arranjo dos canais, que pode ser denominado com uma "Drenagem Dendrítica" devido o seu desenvolvimento assemelhar-se à configuração de uma árvore. Dessa forma a corrente principal corresponde ao tronco da árvore, os 


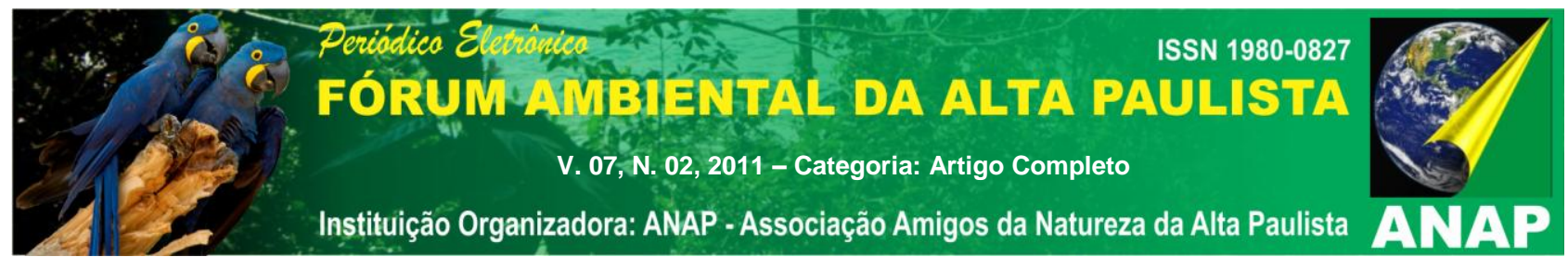

tributários aos seus ramos e as correntes de menor categoria aos raminhos e folhas. (MACHADO, 2008).

Em qualquer bacia o arranjo hidrográfico é a configuração dos canais fluviais que refletem a estrutura geológica e a evolução morfogenética da região. Essas configurações definem "Modelos ou Padrões de Drenagem".

A hierarquia da $\mathrm{MBCl}$ tem classificação máxima de quatro na foz pela classificação do Arthur STRAHLER (1952). Pela classificação temos no total, baseado no modelo de STRAHLER (1952), de 43 rios de $1^{\text {a }}$ ordem, 10 de $2^{\underline{a}}$ ordem, quatro de $3^{\text {a }}$ ordem e um de $4^{\mathrm{a}}$ ordem. Segundo MACHADO (2008)

\begin{abstract}
Os rios de $1^{\text {a }}$ ordem correspondem às áreas de nascentes, caracterizadas por serem mais elevadas e de maiores declividades. Nesse caso, esses cursos d'água têm regime mais turbulento e irregular e são caracterizados mais por sua velocidade do que por seu volume. Esses cursos d'água têm respostas mais rápidas às precipitações, com repentino aumento da vazão, assim como são rápidos em retornar à situação natural. Têm grande capacidade erosiva e transportam sedimentos de considerável granulometria. Suas águas tendem a ser mais transparentes e menos poluídas (MACHADO, 2008).
\end{abstract}

A densidade da drenagem da $\mathrm{MBCl}$ é outro fator importante a ser analisado, pois segundo GRANELL-PEREZ (2001) apud MACHADO (2008) é a densidade da drenagem que informa o comprimento $(\mathrm{km})$ de canal fluvial disponível para drenar cada unidade de área da bacia $\left(\mathrm{km}^{2}\right)$ e, em consequência, informa também, indiretamente, sobre a disponibilidade do escoamento hídrico superficial.

Analisar a densidade é um fator para verificar maior ou menos escoamento que provocará maior ou menos intensidade dos processos erosivos na esculturação dos canais (BELTRAME,1994 apud MACHADO, 2008) A densidade pode ser calculada a partir da equação:

$$
D_{d}=\frac{L_{t}}{A}
$$

Onde Dd é a densidade de drenagem; Lt é o comprimento total dos canais e A é a área da bacia hidrográfica. Substituindo os valores da bacia, tem $A=21 \mathrm{~km}^{2} \mathrm{e} \mathrm{Lt}=47,5$ 


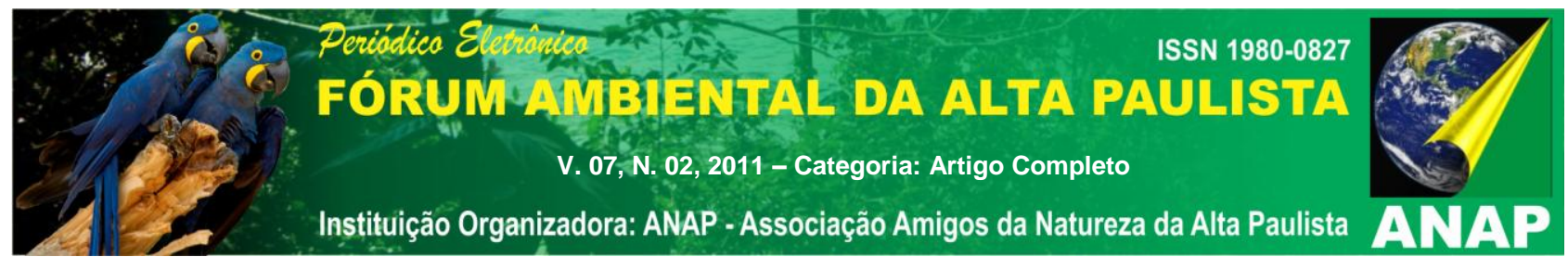

$\mathrm{km}$. A drenagem da $\mathrm{MBCl}$ equivale a 2,26 km/ km². Pela classificação de BELTRAME (1994) este valor da Dd de $2,26 \mathrm{~km} / \mathrm{km}^{2}$ é considerado alto.

Para GRANELL-PEREZ (2001) apud MACHADO (2008) uma Dd alta é indicadora de boa disponibilidade hídrica em superfície, de rochas pouco resistentes, de solos impermeáveis, de escassa cobertura vegetal ou de relevo acidentado, podendo ou não ser compartilhadas simultaneamente todas estas características.

Para COSTA \& TEUBER (2001) apud MACHADO (2008) bacias com densidade de drenagem mais elevada, isto é, mais ramificações na drenagem natural, tendem, em geral, defasar as contribuições parciais e atenuar os hidrogramas de enchentes.

Outra análise que deve ser feita em uma bacia é calcular o coeficiente de manutenção de uma bacia. Esse índice, proposto por SCHUMM (1956), tem a finalidade de fornecer a área mínima necessária para a manutenção de um metro de canal de escoamento. Tem por objetivo revelar a área mínima necessária $\left(e m \mathrm{~m}^{2}\right)$ para a manutenção de um metro de canal de escoamento permanente.

GRANELL-PEREZ (2001) apud MACHADO (2008) indica uma área necessária para manter ativo um km de canal fluvial. O coeficiente de manutenção é um dos índices mais importantes para a caracterização do sistema de drenagem. $O$ coeficiente pode ser calculado pela equação:

\section{$C m=\frac{1}{D d}$}

Substituindo os valores para a micro-bacia do Ipiranga teremos um coeficiente de manutenção igual a $0,4424 \mathrm{~km}^{2} / \mathrm{km}$ ou $44,24 \mathrm{ha} / \mathrm{km}$ ou $442.477 \mathrm{~m}^{2} / \mathrm{km}$.

Mais uma análise a ser feita na $\mathrm{MBCl}$ é a forma da bacia. Para VILELA \& MATOS (1975) apud MACHADO (2008)

a forma da bacia superficial de uma bacia hidrográfica é importante devido ao tempo de concentração, definido como o tempo, a partir do inicio da precipitação, necessário para que toda a bacia contribua na seção em estudo ou, em outras palavras, tempo que leva a água dos limites da bacia para chegar à saída da mesma. 


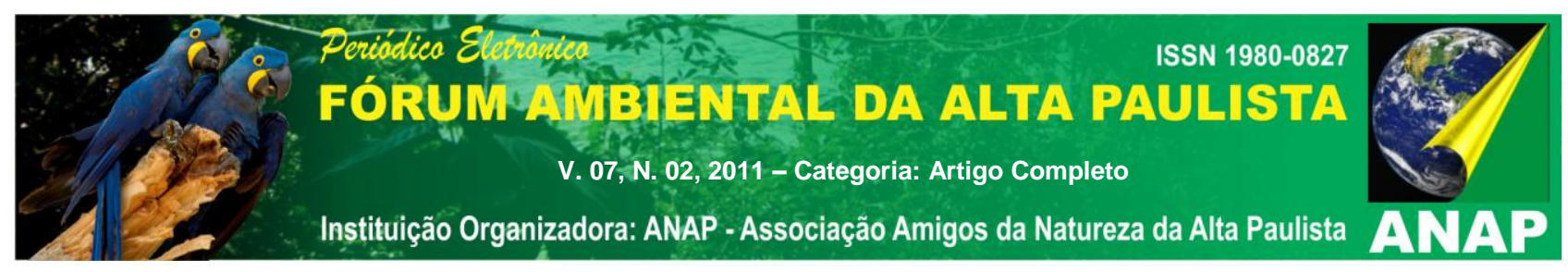

Existem vários índices utilizados para determinar a forma da bacia. Trabalho com a do índice de circularidade (Ic), que pode ser definido como "a relação existente entre a área da bacia e a área do circulo de mesmo perímetro (CHRISTOFOLETTI, 1980) apud (MACHADO, 2008)". A equação seguinte é utilizada para realizar o cálculo:

\title{
$\mathrm{Ic}=\frac{\mathrm{A}}{\mathrm{Ac}}$
}

Onde A é a área da micro-bacia, Ac é a área do círculo, e Ic é o Índice de Circularidade. Para encontrar Ac se utiliza a seguinte equação:

$$
C=2 \pi \cdot r \quad r=C / 2 \pi \quad A c=\pi \cdot r^{2}
$$

Substituindo os valores o $r=3,821656 ; A c=45,84 \mathrm{~km}^{2} ; \mathrm{lc}=0,453$. Quando se calcula o valor de Ic de uma bacia, os valores variam de 0,0 a 1,0 no qual quanto mais próximo de 0 (zero) maior a probabilidade de inundação (caracterizando uma bacia mais estreita e alongada) e quanto mais próximo de 1 (um) menor a probabilidade de inundação (caracterizando uma de forma mais circular).

Segundo GRANELL-PEREZ (2001) apud MACHADO (2008)

\begin{abstract}
as bacias mais circulares apresentam maior risco de provocarem enchentes súbitas no canal principal quando precipitações intensas afetam toda a extensão da bacia, pois o aporte de água no canal fluvial, procedente das vertentes e dos tributários, tende à simultaneidade, concentrando-se num curto espaço de tempo (pico de vazão ou deflúvio). Nesse tipo de bacia recomenda-se manter abundante cobertura vegetal para facilitar o processo de infiltração da água, bem como aplicar praticas de conservação do solo. Nas bacias alongadas, o mesmo fenômeno pluviométrico gera um escoamento melhor distribuído temporalmente no canal principal, o que diminui o risco de enchentes, embora o nível de vazão alta seja mais durável.
\end{abstract}

Assim, com apenas algumas análises morfometricas da bacia é possível identificar que a $\mathrm{MBCl}$ tem facilidades que condicione a ocorrência de inundações devido a toda a suas características, forma e densidade da drenagem. Mas, para a ocorrência de inundações é necessário analisar muito mais do que os dados morfometricos. É 


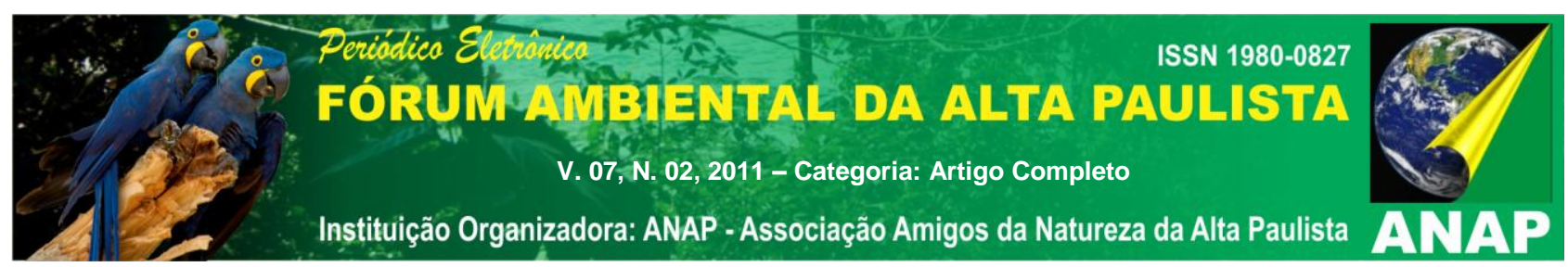

necessário analisar o grau de impactos ambientais e as condições estruturais que o local está inserido.

\title{
1.2.3 Os Impactos Ambientais: as inundações
}

TUCCI (1999) apresentam os seguintes resultados sobre impactos urbanos associados a bacias hidrográficas junto com a urbanização:

\begin{abstract}
a medida que a cidade se urbaniza, em geral, ocorrem os seguintes impactos: aumento das vazões máximas (em até 7 vezes, Leopold,1968) devido ao aumento da capacidade de escoamento através de condutos e canais e impermeabilização das superfícies; aumento da produção de sedimentos devido a desproteção das superfícies e a produção de resíduos sólidos (lixo); e a deterioração da qualidade da água superficial e subterrânea, devido a lavagem das ruas, transporte de material sólido e as ligações clandestinas de esgoto cloacal e pluvial e contaminação de aqüíferos; devido a forma desorganizada como a infra-estrutura urbana é implantada, tais como: (i) pontes e taludes de estradas que obstruem o escoamento; (ii) redução de seção do escoamento aterros; (iii) deposição e obstrução de rios, canais e condutos de lixos e sedimentos; (iii) projetos e obras de drenagem inadequadas.
\end{abstract}

$\mathrm{Na}$ micro-bacia do córrego Ipiranga, encontramos impactos ambientais gerados pelos homens como: córregos canalizados, lixos pelas ruas e dentro do próprio córrego, desmatamentos que favorecem a erosão, impermeabilizações, entre outros. As alterações estão presentes na $\mathrm{MBCl}$ devido ao mal planejamento da área. Ocupações desorganizadas na década de 30-40, e o não cumprimento das leis que protegem os leitos d'água contribuíram para agravar os impactos ambientais.

Além do mal planejamento, córregos canalizados, ordenações de residências incorretas, as precipitações são outro fator que contribuem no aumento de chances de ocorrência de inundações. Sobre o fator pluviosidade, CONTI (1998:34/35) apud MACHADO (2008) coloca que

as chuvas podem ser consideradas intensas a partir de $30 \mathrm{~mm} / \mathrm{h}$ e criticas quando ultrapassam $50 \mathrm{~mm} / \mathrm{h}$. Nessas ocasiões ocorrem verdadeiros traumas ambientais, uma vez que a capacidade dos canais do sistema hidrográfico é insuficiente para conduzir as águas, causando transbordamentos que, em áreas densamente ocupadas, irão provocar grandes desastres. 


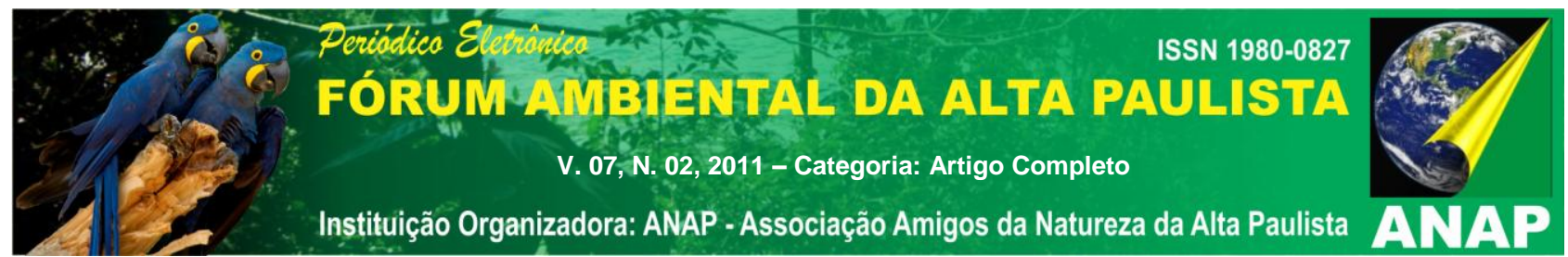

Dessa forma, caso aconteça precipitações com altas intensidades no local, essa trará perigo para a população e danos à natureza. Os danos podem ser maiores quando precipitações com altas intensidades atingirem áreas ocupadas irregulares e sem estrutura, pela população de uma cidade qualquer.

Quanto aos impactos na $\mathrm{MBCl}$, as áreas mais alteradas foram as primeiras a serem loteadas nos anos 30-40, que é a região leste da micro-bacia. A oeste, a ocupação é menor, mas é uma área de crescimento da cidade na qual essa sofre com a criação de acessos para transportes, especulação imobiliária, acesso fácil a BR-040 e a intensa retirada de vegetação, no qual favorece o crescimento da malha urbana. Nessa área de crescimento é interessante ser feito políticas públicas para melhor qualidade de vida da população que venha a se instalar no local e que essas políticas também minimizem os impactos ambientais.

Da área da $\mathrm{MBCl}$, mais de $76 \%$ dela está urbanizada ou não possui nenhum tipo de vegetação que favoreça a proteção de leitos d'água. Os $24 \%$ de vegetação densa restantes, pode ser ainda menor, pois a base de dados utilizada para criar o mapa é de junho de 2006. Dessa data até hoje, teve um aumento da população de Juiz de Fora, o que aumentou a demanda por moradias e lotes para construção de residências.

O mapa a seguir, mostra como é o uso do solo. Foram utilizadas três categorias diferentes (vegetação, capoeira (pasto) e urbanização). 

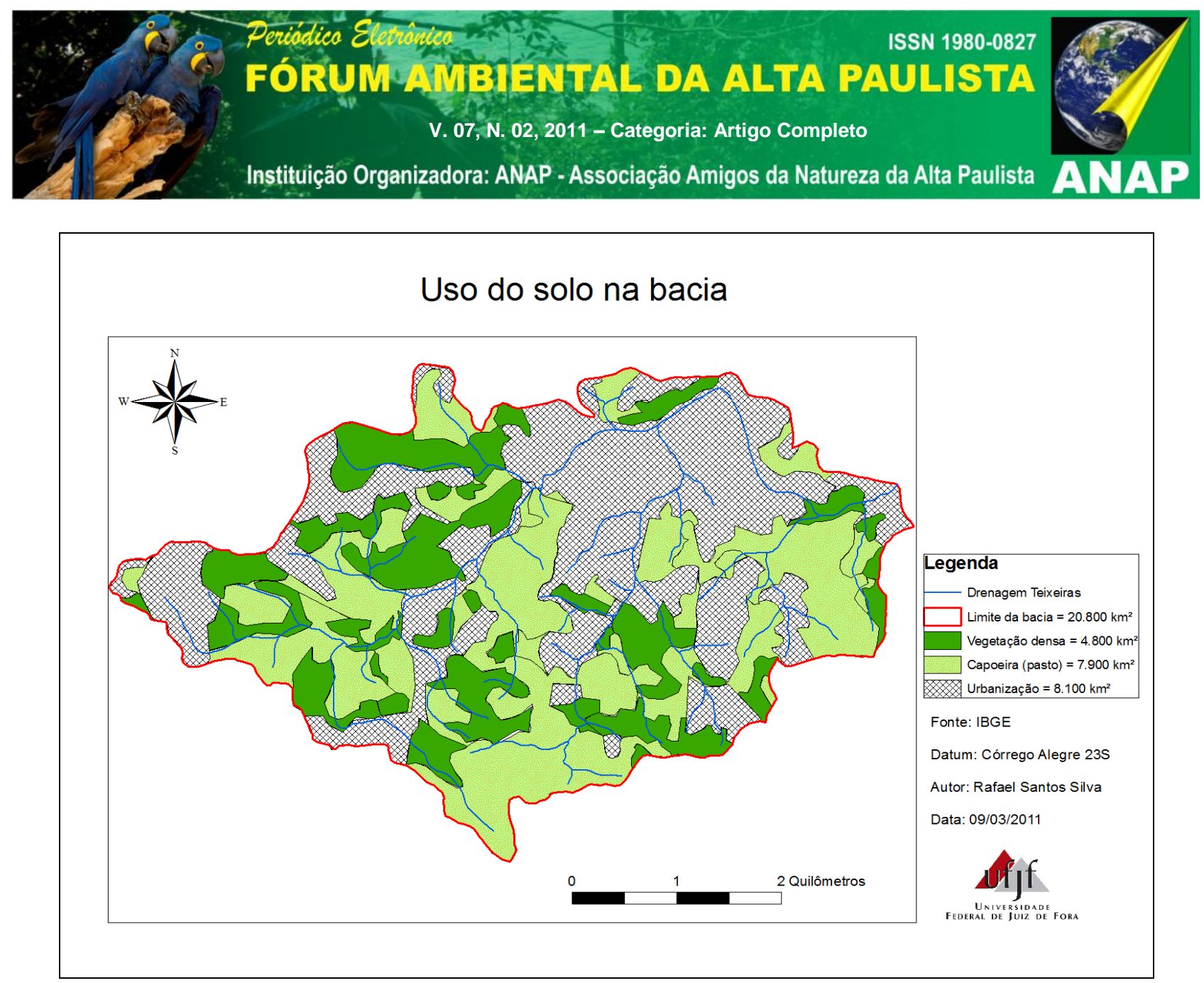

Mapa 02. Uso do solo na MBCI. Fonte: arquivo pessoal do autor, 2011

Como principais causas de alteração, podemos citar as atividades humanas, o uso de solo e as formas de organização no espaço do homem. Dessas mudanças, podemos destacar a desconfiguração (ou configuração) como: construção de edifícios e casas, impermeabilização do solo, retirada de mata ciliar e asfaltamento de ruas.

Os efeitos dessas construções e ordenação do espaço físico criam muitas situações (dificuldade de infiltração, enchentes, desconfiguração da bacia, desaparecimento de nascentes, mudança no ciclo hidrológico, etc.), que altera o equilíbrio natural da microbacia, que favorece a inundações.

A ocupação da $\mathrm{MBCl}$ teve uma tendência de seguir o traçado dos córregos ao longo de suas margens o que dificultou a existência de matas ciliares em torno dos leitos d'água. A canalização do córrego é um dos agravantes das enchentes no local, pois a largura do córrego foi reduzida em quase metade do seu tamanho original. A canalização aumenta a velocidade da água e consequentemente o seu poder de destruição a jusante. Assim, a canalização propicia a ocupação e a utilização de áreas sujeitas à inundação, além de exterminar a biota dos rios e das baixadas. 


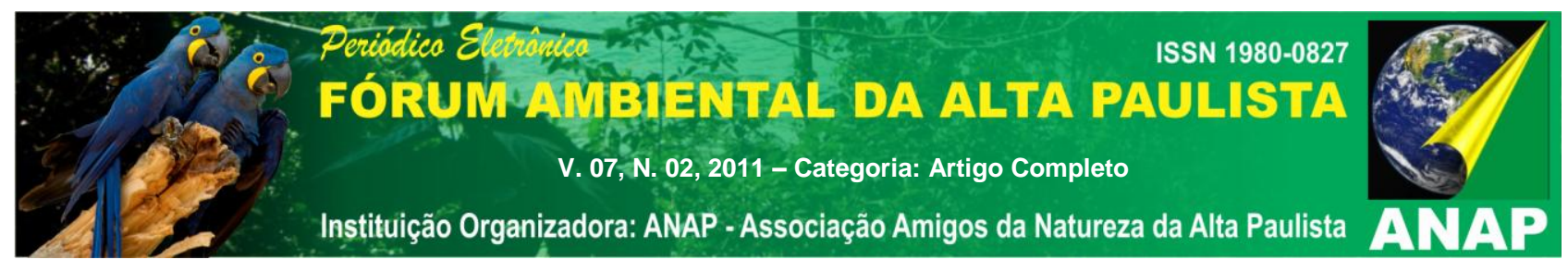

Segundo POMPÊO (2000)

\begin{abstract}
o desmatamento e a substituição da cobertura vegetal natural são fatores modificadores que, em muitas situações, resultam simultaneamente em redução de tempos de concentração e em aumento do volume de escoamento superficial, causando extravasamento de cursos d'água.
\end{abstract}

Quando há presença de vegetação nas vertentes e nas margens dos cursos d'água, obriga-se a água a infiltrar no ponto mais distante entre a sua entrada e saída da bacia hidrográfica. As árvores funcionam como obstáculo para que a água não escoe de maneira rápida, fazendo a lixiviação do solo, e que não acelere o escoamento superficial aumentando a vazão do leito.

$\mathrm{Na} \mathrm{MBCl}$, existe um ponto que apresenta uma maior concentração de população que fica no bairro de Santa Luzia. O local é o centro comercial de Santa Luzia. Esse lugar é um dos locais onde o córrego canalizado muda de sentido bruscamente (quase 90) , não dando tempo e nem espaço necessário para o córrego seguir o seu caminho.

Esse local quando acontece uma precipitação com $\mathrm{mm} / \mathrm{h}$ muito alta, sempre é afetado por inundações, mesmo que seja por um curto tempo e não provocando perdas materiais.

\title{
3 CONCLUSÃO
}

As alterações presentes na $\mathrm{MBCl}$ devido às ocupações que ocorreram de forma desorganizada na década de 30-40, e o não cumprimento das leis que protegem os leitos d'água, contribuíram para agravar os impactos ambientais na região. Com a falta de planejamento do local podemos indicar alguns impactos sofridos na região pelos efeitos da urbanização mal planejada. São eles: i) alteração da cobertura natural do solo; ii) impermeabilização do solo; iii) canalização dos cursos d'água; iv) alterações no relevo local; e, v) diminuição do tempo de concentração de água nas bacias.

Atualmente, a micro-bacia tem alta densidade urbana e não apresenta nenhum tipo de vegetação que proteja os rios e nascentes. As causas desta alteração são as atividades humanas, a ocupação e o uso do solo e a falta de gerenciamento das bacias pelo município. 
A falta de planejamento da $\mathrm{MBCl}$ que apresenta um relevo com alta declividade e com histórico de inundações necessita de um plano de ordenamento territorial e ambiental para diminuir as degradações que aumentam a cada ano.

Portanto, analisar as contradições entre o uso do solo e o seu relevo, e entre a forma da bacia e a ocupação urbana é um fator importante para se planejar, organizar e construir uma cidade mais adequada tanto aos aspectos ambientais quanto às necessidades do homem.

\section{REFERÊNCIAS}

CESAMA, Companhia de Saneamento Municipal de Juiz de Fora. Disponível em: http://www.cesama.com.br/pesquisaescolar. Acesso em: 08/09/2010

Anuário Estatístico de Juiz de Fora, 2010. Disponível em: www.cps.ufj.br. Acesso em: $22 / 11 / 2010$

IGCE/DGA. GEOLOGIA AMBIENTAL: Enchentes e inundações, 2004

MACHADO, P. J. de O. Apostila de Hidrogeografia. Juiz de Fora: UFJF, ano. (Notas de aula).

NASCIMENTO, W. M. do; Villaça, M. G. Bacias Hidrográficas: Planejamento e Gerenciamento. Revista Eletrônica da Associação dos Geógrafos Brasileiros - Seção Três Lagoas. Três Lagoas - MS - № 7 - ano 5, Maio de 2008

POMPÊO, C. A. Drenagem Urbana Sustentável. Revista Brasileira de Recursos Hídricos, n.1, p. 15-23, Jan/Mar, 2000

TUCCI, C. E. M. Drenagem Urbana e Controle de Inundação. São Paulo, Editora da Unisinos. 1999

VENDRAME, I. F. LOPES W. A. B. Análise do crescimento urbano e seus efeitos na mudança da dinâmica de escoamento superficial da bacia do Pararangaba. Anais XII Simpósio Brasileiro de sensoriamento Remoto. Goiânia, INPE, 2005 